\title{
Different responses of supraventricular tachycardia with 2:1 AV block to consecutive premature ventricular contractions
}

\author{
Svetoslav Kurtev MD iD | Cristina Valduva MD | László Sághy MD, PhD | \\ Robert Pap MD, PhD
}

2nd Department of Medicine and Cardiology Center, University of Szeged, Szeged, Hungary

Correspondence

Svetoslav Kurtev, MD, EP Fellow, 2nd Department of Medicine and Cardiology Center, University of Szeged, Semmelweis str. 8, 6725 Szeged, Hungary. Email:svetlyo.kurtev@gmail.com

KEYWORDS: atypical AVNRT, infranodal block

\section{1 | CASE}

A 52-year-old female was admitted with complaints of palpitations for 2 years. The transthoracic echocardiography and electrocardiogram were both normal at the time of admission. We performed an electrophysiology study where the baseline intervals were in normal range. During burst atrial pacing, we observed His ventricular interval $(\mathrm{HV})$ prolongation ( $\mathrm{HV}=80 \mathrm{~ms}$ ) and infra-Hisian block. After the administration of isoproterenol $1 \mathrm{mcg} / \mathrm{min}$, with burst atrial pacing we induced a narrow QRS complex tachycardia with Note that 2:1 atrioventricular interval (AV) block, cycle length (CL) of $270 \mathrm{~ms}$, atrium His interval of $95 \mathrm{~ms}$, and ventricular atrial (VA) interval of $140 \mathrm{~ms}$. A spontaneous premature ventricular complex (PVC) was followed by restoration of 1:1 $\mathrm{AV}$ conduction during tachycardia with the same $\mathrm{CL}$ and VA interval. After entrainment of the tachycardia by ventricular overdrive pacing, we observed a $\mathrm{VA}(\mathrm{H}) \mathrm{V}$ response. The postpacing interval minus tachycardia CL was $180 \mathrm{~ms}$ and stimulus atrial VA was $180 \mathrm{~ms}$, respectively. We intriguingly observed that before the transformation of the tachycardia from 2:1 to 1:1 AV conduction by the PVC, a previous PVC with the same morphology occurred which did not result in resumption of $1: 1$ conduction. This finding raised the question: why two morphologically similar PVCs have led to different responses of the tachycardia? (Figure 1).

\section{2 | COMMENTARY}

The differential diagnosis of a narrow QRS complex tachycardia, with 2:1 AV block includes AV-nodal reentry tachycardia (AVNRT) and atrial tachycardia (AT). The observation of a $\mathrm{VA}(\mathrm{H}) \mathrm{V}$ response after ventricular entrainment effectively rules out AT, leaving AVNRT the diagnosis. The occurrence of 2:1 AV block during AVNRT is a wellknown phenomenon, ${ }^{1-3}$ with an incidence of around $10 \% .{ }^{4}$ It has been described during atypical AVNRT also, ${ }^{5}$ as in our case. Although the site of AV block is debated, most likely it is infranodal, at least in the majority of the cases. ${ }^{4}$ No correlations between the emergence of the block and pathologic AV block, demographic variables, and HV prolongation have been found. In our case, we observed a normal baseline $\mathrm{HV}$ interval ( $\mathrm{HV}=45 \mathrm{~ms}$ ); however, there was a significant prolongation during burst atrial pacing $(\mathrm{HV}=80 \mathrm{~ms})$ and infra-Hisian block. During tachycardia with 2:1 AV block, His bundle potentials of blocked beats were well discernable, but right bundle branch (RBB) potentials recorded on the right ventricular catheter were missing, indicating that the site of the block was in the distal His-bundle (Figure 1). The two consecutive PVCs had left bundle branch (LBB) block-like morphology and neither influenced the timing of His-potentials (both are Hisrefractory). After the first PVC, there was a transient improvement in His-Purkinje system (HPS) conduction since tachycardia beat number six $(\mathrm{H} 6)$ conducted to the ventricles. This beat was destined to be blocked, based on the 2:1 conduction pattern-if the PVC had not occurred. Subsequently, however, H7 blocks, therefore 1:1 AV conduction, had not been restored until the second PVC, which had a longer coupling interval than the first. The commonly accepted explanation for resumption of conduction in this scenario is retrograde penetration by the PVC into the region of block in the HPS, preexciting it and at the same time shortening its (CL-dependent) refractoriness, a phenomenon termed "peeling back" of refractoriness. ${ }^{6}$ While the first PVC clearly influenced the conduction (since $\mathrm{H} 6$ can conduct), it did not result in the resumption of 1:1 conduction. This was accomplished by the second PVC occurring later in the cycle.

Even though the first PVC came earlier, it exerted less influence on HPS conduction, compared to the second, which had a longer coupling interval. The likely explanation is that the retrograde impulse from the first PVC reaches the site of HPS block actually later despite originating earlier (Figure 2). Both PVCs originate from the right ventricle, but the first one is earlier and finds the RBB refractory from the previous impulse, so it can only conduct transseptally and then up the LBBthat has a shorter refractoriness than the RBB-to reach the site of block in the HPS. This is a preexcited, but not sufficiently to "peel back" 


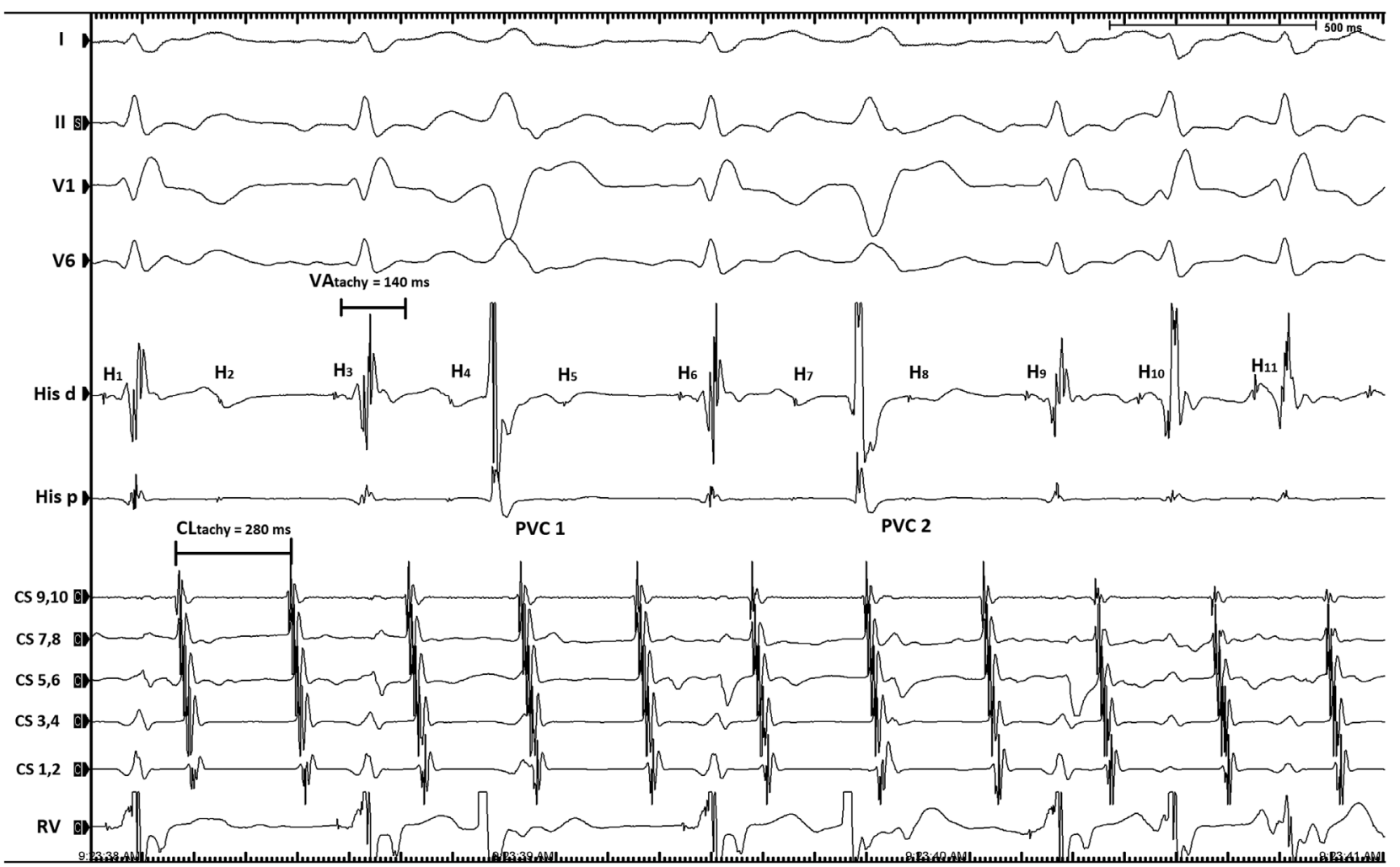

FIGURE 1 Surface ECG (leads I, II, V1, and V6) and intracardiac electrogram tracing during atypical AVNRT with a CL of 270 ms and VA 140 ms. The first PVC (PVC 1) does not restore 1:1 conduction, but the second premature PVC (PVC2) leads to resumption of 1:1 conduction of the tachycardia. Letter $\mathrm{H}$ in His, d channel indicates the His potential. AVNRT = atrioventricular nodal reentry tachycardia; $\mathrm{CL}=\mathrm{cycle}$ length; $\mathrm{CS}=\mathrm{coronary}$ sinus electrode; $\mathrm{ECG}=$ electrocardiogram; $\mathrm{His} \mathrm{d}=$ distal $\mathrm{His}$ bundle electrode; $\mathrm{His} \mathrm{p}=$ proximal His bundle electrode; $\mathrm{PVC}=$ premature ventricular contraction; $\mathrm{RV}=$ right ventricular electrode; $\mathrm{VA}=$ ventricular atrial interval

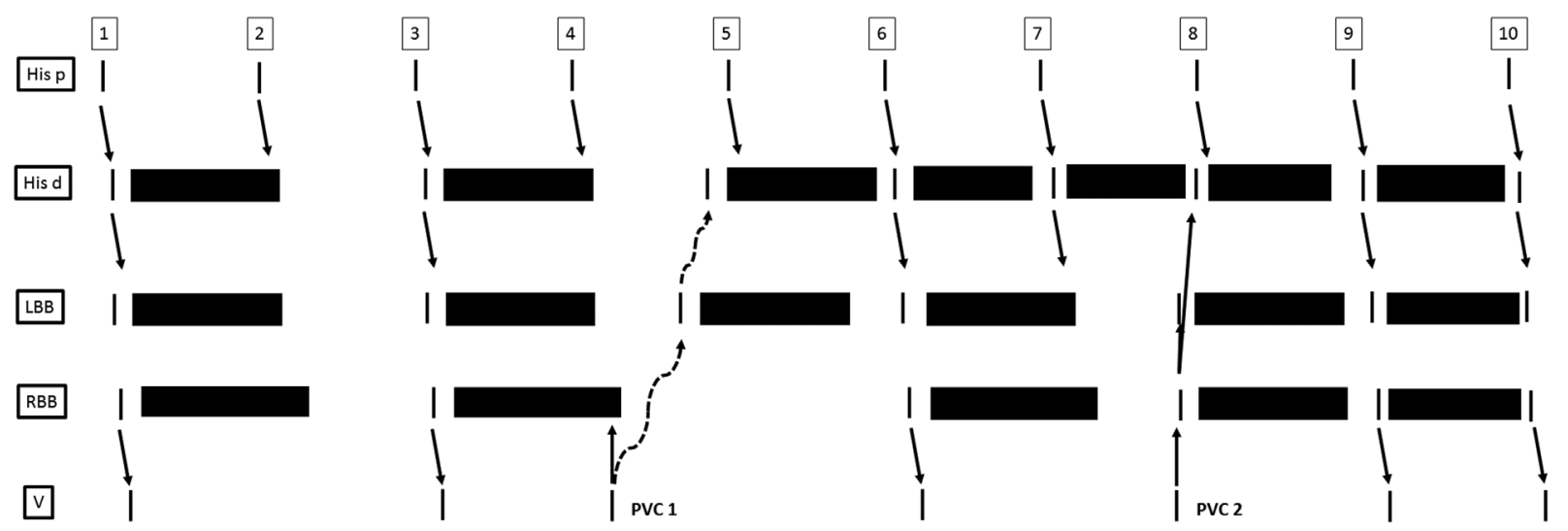

FIGURE 2 Schematic representation of the intracardiac electrogram tracing on Figure 1. Digits from 1 to 10 designate the tachycardia complexes corresponding to the relevant His potentials on Figure 1. The black rectangles denote ERP of His distal (His d), LBB, and RBB of the conduction system. The first PVC reaches the RBB during ERP from the previous beat and the impulse has to pass transseptally in order to reach the LBB. Although the second PVC arrives with a longer coupling interval, it can conduct retrogradely up to the RBB, thereafter reaches the site of the block to preexcite, shorten its refractoriness, and eventually resume 1:1 conduction of the tachycardia. ERP = effective refractory periods; LBB = left bundle branch; PVC = premature ventricular contraction; RBB = right bundle branch

refractoriness of the HPS, therefore although the next beat $(\mathrm{H} 6)$ conducts, yet 2:1 block is not terminated. Subsequently, the second PVC arrives with a longer coupling interval that can now conduct retrogradely up the RBB and reach the site of block to preexcite and shorten its refractoriness; therefore, 1:1 conduction is resumed (Figure 2).

\section{3 | CONCLUSION}

Stepwise resumption of 1:1 AV conduction during AVNRT by consecutive PVCs demonstrates the mechanism of retrograde penetration, preexcitation, and "peeling back" of refractoriness in the HPS. 


\section{CONFLICT OF INTEREST}

The authors declare that there is no conflict of interests regarding this publication.

\section{ORCID}

Svetoslav Kurtev MD (iD http://orcid.org/0000-0003-1068-9086

\section{REFERENCES}

1. Schmitt C, Miller JM, Josephson ME. Atrioventricular nodal supraventricular tachycardia with 2:1 block above the bundle of His. Pacing Clin Electrophysiol. 1988;11:1018-1023.

2. Miles WM, Hubbard JE, Zipes DP, Klein LS. Elimination of AV nodal reentrant tachycardia with 2:1 VA block by posteroseptal ablation. J Cardiovasc Electrophysiol. 1994;5:510-516.

3. Wellens HJJ, Wesdorp JC, Duren DR, Lie KI. Second degree block during reciprocal atrioventricular nodal tachycardia. Circulation. 1976;53:595599.
4. Man KC, Brinkman K, Bogun F, et al. 2:1 atrioventricular block during atrioventricular node reentrant tachycardia. J Am Coll Cardiol. 1996;28:1770-1774.

5. Sorgente A, Chierchia GB, De Asmundis C, Yazaki Y, Sarkozy A, Brugada P. Stepwise transition of 2:1 atrioventricular block to 1:1 conduction induced by ventricular premature beats in a patient with atypical AVNRT. Pacing Clin Electrophysiol. 2010;33:e20-23.

6. Moe GK, Chllders RW, Meredith J. An appraisal of "supernormal" A-V conduction. Circulation. 1966;36:5-28.

How to cite this article: Kurtev S, Valduva C, Sághy L, Pap R. Different responses of supraventricular tachycardia with 2:1 AV block to consecutive premature ventricular contractions. Pacing Clin Electrophysiol. 2018;1-3. https://doi.org/10.1111/pace.13283 